\title{
Assessment and diagnosis of dementia: a review for primary healthcare professionals
}

\author{
K Lam, Windy SY Chan, James KH Luk, Angela YM Leung *
}

\section{A B S T R A C T}

Dementia is one of the most costly, disabling diseases associated with ageing, yet it remains underdiagnosed in primary care. In this article, we present the comprehensive approach illustrated with a classical case for diagnosing dementia which can be applied by healthcare professionals in primary care. This diagnostic approach includes history taking and physical examination, cognitive testing, informant interviews, neuropsychological testing, neuroimaging, and the utility of cerebrospinal fluid biomarkers. For the differential diagnosis of cognitive impairment, the differences and similarities among normal ageing, mild cognitive impairment, depression, and delirium are highlighted. As primary care physicians are playing an increasingly

This article was published on 4 Dec 2019 at www.hkmj.org. prominent role in the caring of elderly patients in an ageing population, their role in the diagnosis of dementia should be strengthened in order to provide a quality care for patients with dementia.
Hong Kong Med J 2019;25:473-82
https://doi.org/10.12809/hkmj198073

\begin{abstract}
${ }^{1}$ K Lam, FRCP (Edin), FHKAM (Medicine)
${ }^{2}$ WSY Chan, MClinPharm, DHSc

3 JKH Luk, FHKCP, FHKAM (Medicine)
\end{abstract}
${ }^{4}$ AYM Leung *, PhD, FHKAN (Geron)
1 Cheshire Home (Shatin), Hospital Authority, Hong Kong
School of Health Sciences, Caritas Institute of Higher Education, Hong Kong
${ }^{3}$ Department of Medicine, Fung Yiu King Hospital, Hong Kong
${ }^{4}$ Centre for Gerontological Nursing, The Hong Kong Polytechnic
University, Hong Kong
* Corresponding author: angela.ym.leung@polyu.edu.hk

\section{Introduction}

Among people aged $>65$ years, the global prevalence of dementia has been estimated as $5 \%,{ }^{1}$ with an overall prevalence of $3.9 \%$ in Asia. ${ }^{2}$ The prevalence increases with ageing, with more than one third of people aged $>85$ years having dementia. ${ }^{1}$ In 2015 , it was estimated that 46.8 million people lived with dementia worldwide, with those numbers expected to almost double every 20 years until reaching 131.5 million in $2050 .^{3}$ In China, the burden of dementia is increasing much more rapidly than previously assumed by the international health community. ${ }^{4}$ Earlier and more accurate detection of dementia is critical because it allows patients to plan their future care while they still have the capacity to make important decisions. ${ }^{5}$ Only through receiving a diagnosis can a person with dementia obtain access to cognitive and pharmacological therapies. However, dementia is underdiagnosed in primary care. Evidence from a primary care-based screening and diagnosis programme in the United States revealed that only $19 \%$ of patients with a confirmed dementia diagnosis had been checked for dementia during routine medical care. ${ }^{6}$

A population-based study showed that approximately $20 \%$ of family informants failed to recognise memory problems in elderly subjects who were found to have dementia on a standardised examination. ${ }^{7}$ A United Kingdom study showed that earlier diagnosis may also ease caregiver concerns. ${ }^{8}$ Planning by families of elderly patients is most effective when dementia is diagnosed early in the course of the illness. Accurate diagnosis with subtyping is the prerequisite for providing optimal therapies specific to different dementia diagnoses. In addition, reversible causes of cognitive impairment, eg, depression, should be looked for. ${ }^{9}$

This article reviews recent approaches in dementia diagnosis and discusses their applications by healthcare professionals, particularly those working in the primary care setting.

\section{Definition of dementia}

The fifth edition of the Diagnostic and Statistical Manual of Mental Disorders (DSM-5) provides a common framework for the diagnosis of neurocognitive disorders, including dementia, which is named 'major neurocognitive disorder' in this edition. ${ }^{10,11}$ It serves as a common linguistic framework to deal with neurocognitive disorders, thus promoting efficient communication among clinicians and researchers. ${ }^{11}$ The criteria for major neurocognitive disorders are summarised in Box 1 .

The major limitation of the DSM-5 is that it requires intellectual deficits to be sufficiently severe to impair social or occupational functioning. Therefore, it necessarily draws an arbitrary line between dementia and the lack thereof. In clinical settings, patients usually pass through stages of intellectual decline, including cognitive deficits 


\section{評估和診斷認知障礙症: 給基礎專業人員的回顧 林娟、陳秀怡、陸嘉熙、梁綺雯}

在老年社會中, 認知障礙症是引致經濟負擔和令患者失去自理能力的 最嚴重的疾病之一, 但在社區中, 患者往往未得到充分診斷。本文回 顧診斷認知障礙症的最新方法, 並解説醫療專業人員如何在基礎醫療 中應用。透過審視病例，本文闡述的診斷方法包括病史和臨床體檢、 認知評估、家人和照顧者訪談、神經心理學測試、神經影像學和腦脊 液中的標誌物。為了幫助鑑別診斷認知障礙, 本文比較正常衰老、輕 度認知障礙、抑稂和譫妄症間的差異和相似性。為了讓老年患者社區 中得到適切的診斷和治療, 基礎醫療在診斷認知障礙症中的角色應予 以加強。 encounters difficulties in recalling memories.

Not all patients with memory loss complaints have dementia. There are four common conditions that primary care doctors need to differentiate from dementia.

\section{Cognitive changes with normal ageing}

The normal cognitive decline associated with ageing consists primarily of mild changes in memory and the rate of information processing and does not usually affect daily functioning. Normative data from crosssectional studies examining neuropsychological performance demonstrate that the ability to perform new learning or acquisition declines with age, whereas cued recall remains stable. ${ }^{12-14}$ Agerelated declines are not inevitable, and when they do occur, careful evaluation for underlying age-related diseases is warranted.

\section{Mild cognitive impairment}

Mild cognitive impairment is defined by the presence of memory difficulty and objective memory impairment but preserved ability to function in daily life.

While cognitive changes with normal age refer to normal age-associated memory and cognitive changes in older adults compared with young normal adults, MCI refers to abnormal changes in cognitive functioning, and the criteria include a measurable cognitive deficit in at least one domain. ${ }^{15-17}$

This condition is considered to be a transitional stage between normal ageing and dementia. There is no pharmacological treatment for MCI at this time. Studies have shown that subjects with MCI followed for up to 4 years have an annual conversion rate ranging from $6 \%$ to $25 \%$, but not all of those with MCI evolve to dementia. ${ }^{18}$ Subjects with MCI may fluctuate between different trajectories of MCI, including normal cognition, MCI, and dementia. ${ }^{19}$ Progression from 'normal to $\mathrm{MCI}$ ' or 'normal to MCI to dementia' is not always linear: subjects who

BOX I. Criteria for major neurocognitive disorders

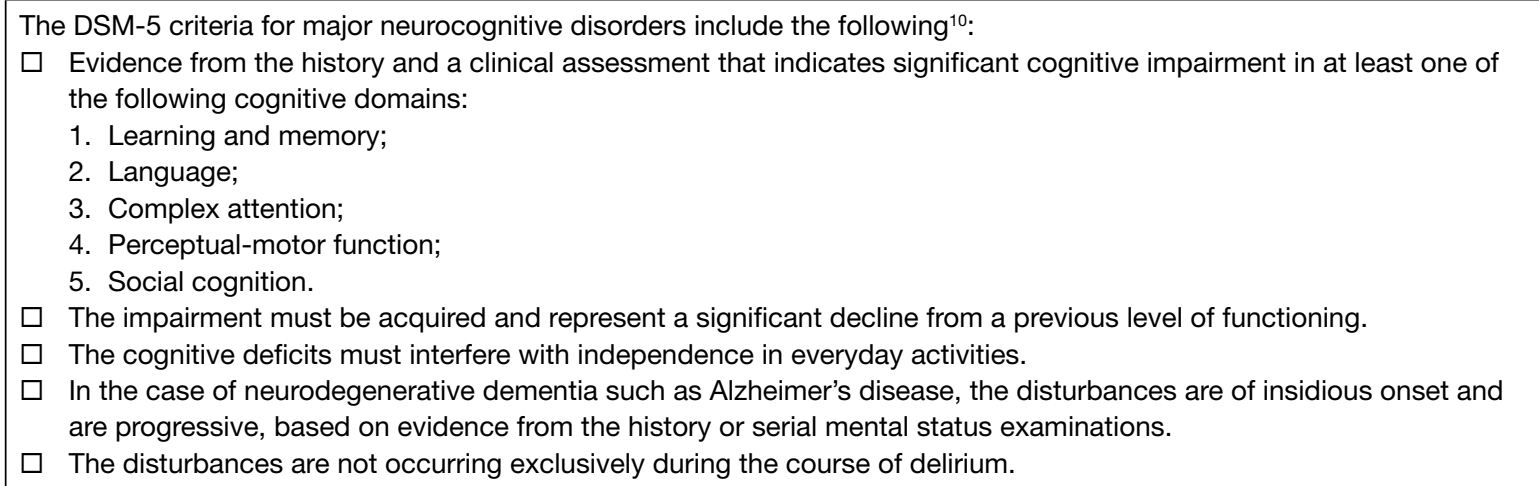

Abbreviation: DSM-5 = The fifth edition of the Diagnostic and Statistical Manual of Mental Disorders 
develop MCI and later return to normal may develop dementia later. ${ }^{20}$ Longitudinal follow-up of MCI subjects is indicated to avoid missing a diagnosis of dementia conversion. ${ }^{20}$ The criteria for minor neurocognitive disorders are summarised in Box 2 .

\section{Depression}

Memory impairment is commonly associated with major depression in elderly people, and it can cause pseudo-dementia syndrome. Patients with depression usually present with persistent sadness, loss of interest in their usual activities, sleep and appetite disturbances, or feelings of worthlessness or guilt. ${ }^{10}$ The most commonly used clinical screening tool for depression is the Geriatric Depression Scale. ${ }^{21}$ Patients with depression may have signs of psychomotor slowing and apply little effort to testing, while those with dementia often try hard but respond with incorrect answers. Antidepressants may improve patients' mood and cognitive symptoms. However, dementia can sometimes co-exist with depression, and treatments may be required for both.

\section{Delirium}

Delirium, or acute confusional state, is another common condition in elderly people. It is usually acute or subacute in onset and is associated with sensory clouding; patients have fluctuations in their consciousness level and have difficulty maintaining attention and concentration..$^{22}$ Delirium is associated with a variety of systemic illnesses, infections, and toxic and metabolic disturbances.

Delirium is uncommon among communitydwelling elderly people. The Canadian Study of Health and Aging found that the prevalence of delirium is $<0.5 \%$ among elderly people living outside of acute care. ${ }^{23}$ Nevertheless, hospitalised elderly patients are more prone to delirium. Studies have shown that approximately $11 \%$ to $25 \%$ of hospitalised older patients have delirium upon admission, and an additional $29 \%$ to $31 \%$ of older patients admitted without delirium will develop it. ${ }^{24,25}$ Elderly patients have a decreased level of brain reserve, which makes them more prone to decompensation during acute stress and the development of delirium.

It is important to recognise that patients with dementia are at increased risk of delirium and that delirium and dementia may coexist. The most commonly used instrument for screening and identifying delirium is the Confusion Assessment Method. ${ }^{26}$ The updated standard diagnostic criteria for delirium are stipulated in the DSM-5.

\section{Aetiology of dementia}

Once a patient is diagnosed with dementia, it is important to determine the underlying aetiologies. These include various neurodegenerative diseases as well as metabolic and toxic causes. Among them, Alzheimer's disease (AD) is the most common cause of dementia in elderly individuals, accounting for $60 \%$ to $80 \%$ of all cases, followed by vascular dementia $(\mathrm{VaD})$, which accounts for about $20 \%{ }^{4,27}$ The distribution of dementia varies across geographical locations and cultural and socioeconomic differences. In the Chinese population, the median proportions of $\mathrm{AD}$ and $\mathrm{VaD}$ in all forms of dementia were around $70 \%$ and $24 \%$, respectively; other forms constituted 7.5\%. ${ }^{4}$ Dementia with Lewy bodies (DLB) is among the most common forms of degenerative dementia, accounting for $4.2 \%$ of all diagnosed dementia cases in the community. 28 Frontotemporal dementia (FTD), Parkinson-plus syndromes, alcohol-related dementia, chronic

BOX 2. Criteria for minor neurocognitive disorders

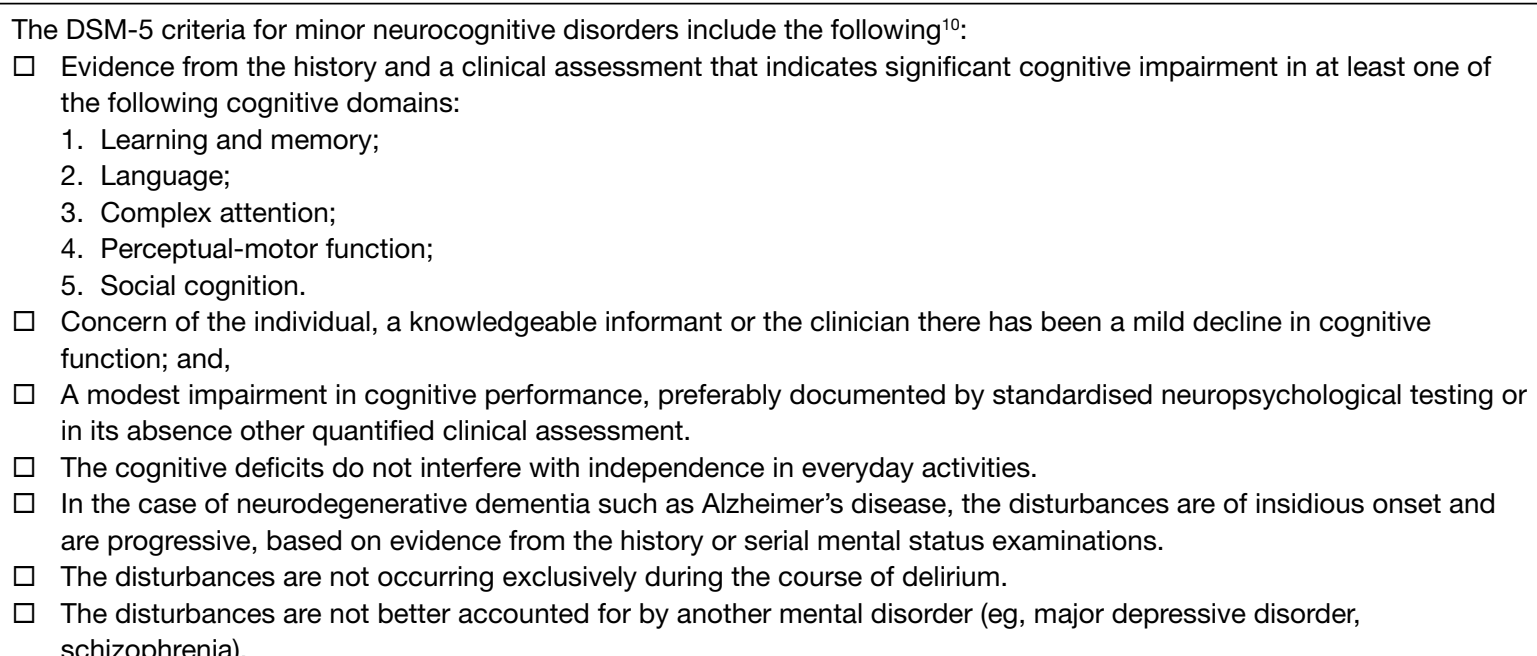

Abbreviation: DSM-5 = The fifth edition of the Diagnostic and Statistical Manual of Mental Disorders 
traumatic encephalopathy, and other central nervous system illnesses are uncommon causes and are responsible for the majority of the remaining chronic dementia cases. ${ }^{12}$

\section{Common subtypes of dementia}

Alzheimer's disease is usually a disease of ageing, and its incidence increases exponentially with age $>65$ years. The onset and progress of AD are insidious, and memory impairment is its most frequent feature. Deficits in other cognitive domains such as executive and visuospatial tend to occur relatively early, while language deficits and behavioural symptoms often manifest later in the course of the disease. ${ }^{29,30}$

Vascular dementia is primarily caused by cerebrovascular disease and/or impaired cerebral blood flow. There are two main syndromes of $\mathrm{VaD}$ : post-stroke dementia and $\mathrm{VaD}$ without recent stroke.

Patients with post-stroke dementia experience a stepwise cognitive decline that may be accompanied by other cortical stroke signs, including aphasia and apraxia, after a clinically diagnosed stroke. In contrast, patients with $\mathrm{VaD}$ without recent stroke present with progressive or stepwise cognitive decline with prominent impairment in executive functioning and processing speed. Brain imaging reveals silent cerebrovascular disease including infarction or haemorrhage and is a required element of some of the commonly used diagnostic criteria for $\mathrm{VaD}$, including the criteria of the NINDS-AIREN (National Institute of Neurological Disorders and Stroke). ${ }^{31,32}$

Dementia with Lewy bodies is a form of dementia caused by abnormal protein structures called Lewy bodies, which co-occur with symptoms of Parkinsonism such as trembling, stiffness, and slowness. Other classical features of DLB include rapid eye movement sleep behavioural disorder and fluctuation of cognition (both are easy to elicit from history). This disorder often causes vivid and longlasting visual hallucinations. Differential diagnosis of DLB includes other degenerative dementias, especially if complicated by superimposed delirium, medication toxicity, or seizures. Diagnosis of DLB is made primarily by the revised criteria for clinical diagnosis. $^{33}$

Frontotemporal dementia is a heterogeneous neurodegenerative disorder characterised by frontal and/or temporal lobe degeneration with early-onset dementia presenting with prominent changes in social behaviour, personality, or aphasia. ${ }^{34}$ There are several clinical presentations: behavioural variant FTD, two forms of primary progressive aphasia (PPA), non-fluent variant PPA, and semantic variant PPA. ${ }^{34}$ Among these, behavioural variant FTD is the most common form, characterised by progressive personality and behavioural changes including disinhibition, apathy, loss of empathy, hyperorality, and compulsive behaviours. The diagnostic criteria for FTD created by an international consortium synthesise clinical features, neuroimaging, neuropathology, and genetic testing. ${ }^{35}$

\section{Behavioural and psychological symptoms of dementia}

Behavioural and psychological symptoms of dementia (BPSD) were defined as 'symptoms of disturbed perception, thought content, mood, and behaviour frequently occurring in patients with dementia' by consensus among clinicians in $1996 .^{36,37}$ More than $50 \%$ of people with dementia have BPSD, and these symptoms affect both patients and their relatives. ${ }^{38} \mathrm{~A}$ wide variety of affective, psychotic, and behavioural symptoms and signs can be signs of BPSD presentation, including verbal and physical aggression, agitation, hallucinations, delusions, sleep disturbances, oppositional behaviour, and wandering. ${ }^{39}$ Non-pharmacological interventions have been beneficial and should be offered as the firstline management. ${ }^{40}$ Indoor therapeutic gardening is an effective non-pharmacological intervention to reduce $B P S D$, medicine intake, and stress levels among patients with AD. ${ }^{41}$ Antipsychotic drugs are the common treatment for BPSD, ${ }^{42}$ but evidencebased clinical practice guidelines recommend deprescribing the drugs when the symptoms have been stabilised or treated for 3 months or more. ${ }^{43}$ Caregivers' burden has been associated with patients' $\mathrm{BPSD}^{44}$; therefore, treating BPSD brings benefits to both patients and caregivers.

\section{Diagnostic approach}

There is no single test to confirm the diagnosis of dementia. Initial assessment should include careful histories from both the patient and caregivers, physical examinations, cognitive assessments, laboratory tests, and neuroimaging.

\section{History and physical examination}

Clinical evaluation of patients with suspected dementia should start with a thorough and detailed history, taken from both the patient and a relative or close friend..$^{45}$ It is important for primary care practitioners to rule out other causes of memory and cognitive impairments and refer appropriate patients for specialist assessment, especially those with unusual symptoms. ${ }^{46}$ A review is necessary of the patient's family history and medical and psychiatric history, including obstructive sleep apnoea, cardiovascular disease, remote head trauma, alcohol use, and depression treatment that may contribute to cognitive decline, as well as the use of drugs that impair cognition (eg, analgesics, anticholinergics, psychotropic medications, and sedative-hypnotics). ${ }^{12,47}$ It is important to note the 
age of onset of cognitive impairment and to ask about family history for patients with cognitive impairment developing at or before age 65 years. Familial AD has been reported in Hong Kong, and these patients may need to be referred for genetic counselling and testing. ${ }^{48,49}$ This should be followed by a complete physical examination, including a neurological examination, to identify any clinical features of obstructive sleep apnoea, focal neurologic signs that may suggest vascular aetiology, or bradykinesia, rigidity, or tremors that would suggest a Parkinsonian syndrome. ${ }^{12}$

\section{Cognitive testing}

Cognitive tests provide objective evidence about cognitive deficits. Nevertheless, a single test will not suffice for all assessments. Different classes of cognitive tests are better suited to different tasks-short questionnaires are useful for rapid screening, but multidomain tests are more useful to support a clinical diagnosis of dementia. ${ }^{50}$ In the primary care setting, abbreviated or brief cognitive instruments such as abbreviated versions of the Montreal Cognitive Assessment (MoCA) and Mini$\mathrm{Cog}$ are recommended in persons with symptoms of dementia. ${ }^{46,51}$

\section{Mini-Mental State Examination}

The Mini-Mental State Examination (MMSE) has been the most commonly used cognitive screening instrument, although patent protection has led to its decreased use in recent years. It has the advantages of being brief, easy to administer, and inclusive of multiple domains, including orientation, recall, attention, calculation, language manipulation, and constructional praxis. ${ }^{52,53}$ Published normative data allow interpretation of MMSE scores according to patient age and education. The maximum score on the MMSE is 30 points. The Cantonese version of the MMSE has been locally validated, and its cut-off points are categorised according to the patient's education level. For patients with more than 2 years of schooling, the cut-off score is $22 .{ }^{54,55}$ The pattern of clinical deficit shown by the MMSE test is also important for the diagnosis of dementia. ${ }^{56}$ However, the test is not sensitive to mild dementia, and scores may be influenced by age, education, and language, motor and visual impairments. 12,57 The MMSE has limited ability to assess progressive cognitive decline in individual patients over time..$^{58}$

Although many 'free' versions of the MMSE are available online, the official version is copyrighted.

\section{Montreal Cognitive Assessment}

The MoCA has become the more widespread initial screening test for dementia. In early 2018, news of the President of the United States having passed the MoCA triggered widespread interest in this test. The MoCA is a 30-point test designed to detect cognitive impairment in older adults. Compared with MMSE, it is more sensitive for detection of $\mathrm{MCI}$ and includes items that sample a wider range of cognitive domains, including memory, language, attention, visuospatial, and executive functions..$^{59}$ Cut-offs should be adjusted based on education level and other appropriate norms. ${ }^{60}$ The original MoCA takes a longer time (approximately 15 minutes) to complete compared with the MMSE. Free access with registration is available from the official website at www.mocatest.org. The MoCA has been validated in different languages, including Chinese. The Hong Kong-MoCA (HK-MoCA) has been shown to have comparable sensitivity to the Cantonese version of the MMSE for detection of MCI. ${ }^{61}$ The optimal cut-off score for HK-MoCA to detect dementia was 18/19 (sensitivity: 0.923; specificity: 0.918). ${ }^{61}$ To facilitate screening in busy clinical settings, a few abbreviated versions of the MoCA have been validated, including the MoCA 5-min protocol, which is feasible for telephone administration. ${ }^{62}$

\section{Clinical Dementia Rating}

Clinical Dementia Rating (CDR) was designed to assess the severity of AD in longitudinal studies and clinical trials. In a semi-structured interview with the patient and caregiver, impairments in six domains (memory, orientation, judgement and problem solving, community affairs, home and hobbies, and personal care) are assessed. ${ }^{63} \mathrm{~A}$ caregiver who knows the patient well should be present for an accurate and valid CDR assessment. The global CDR score is assigned based on performance in each domain. It is time-consuming, but the test has established validity and inter-rater reliability and is useful for following disease progression over time. ${ }^{64}$

\section{Mini-Cog test}

The Mini-Cog test consists of two components: a three-item recall test for memory and a simply scored clock drawing test. The assessment and instructions can be accessed at www.mini-cog.com. The results of the clock drawing test are considered normal if all numbers are present in the correct sequence and the hands display the correct time in a readable way ${ }^{65}$ The advantages of the Mini-Cog include high sensitivity for predicting dementia status, short testing time relative to the MMSE, ease of administration, and diagnostic value not limited by the subject's education or language. Nevertheless, these tests are not appropriate when assessing patients with aphasic or anomic disorders, and more prospective data are required for further validation of this test. ${ }^{66}$ 


\section{Informant interview}

The AD8 Dementia Screening Interview is a brief, eight-item questionnaire for informants to detect dementia and cognitive impairment. Informants are asked whether the patient has exhibited any increase in eight deficits or behaviours. A positive response to two or more questions had a sensitivity of $93 \%$ and a specificity of $46 \% .{ }^{67}$ The AD8 is readily administered by nurses and is useful as a screening tool by primary healthcare doctors. ${ }^{68}$ The interview questions and scoring guidelines can be accessed from Washington University in St Louis at http://alzheimer.wustl.edu/ cdr/ad8.htm.

\section{Neuropsychological testing}

Neuropsychological testing usually involves an extensive evaluation of multiple cognitive domains (eg, attention, orientation, executive function, verbal memory, spatial memory, language, calculations, mental flexibility, and conceptualisation) and may be necessary when the bedside assessment fails to differentiate between the changes associated with normal ageing and early dementia. Moreover, neuropsychological testing can identify patterns of deficits that suggest a particular cause of dementia and assist in narrowing the differential diagnosis of dementia syndrome. However, these scores can also be influenced by education and age. ${ }^{18,69}$

\section{Diagnosing Mrs Wong's dementia}

Mrs Wong scored 18 on the HK-MoCA assessment, which was the cut-off score for dementia adjusted by her age and education level.

Mrs Wong presented with a memory complaint evidenced by the collateral history from her family members. In her daily life, she was noted to have impaired executive functioning (inability to handle banking) and topographic disorientation (getting lost while shopping alone). Her HK-MoCA score also confirms the presence of memory impairment. Moreover, her impairment has reached the point of interfering with her social functioning. Therefore, Mrs Wong meets the clinical definition of dementia.

\section{Neuroimaging}

Although the literature regarding indications for neuroimaging in evaluating dementia remains inconclusive, most dementia specialists suggest that a structural brain image be obtained for newly diagnosed patients to assess any cerebrovascular lesions, neoplasms, subdural haematomas, or hydrocephalus. Imaging analysis techniques that quantify the volume of brain structures or lesions may be useful in the future for diagnosing AD. Fluorodeoxyglucose positron emission tomography (FDG-PET) and other functional neuroimaging techniques are usually used by specialists to assess complex or unclear cases of neurodegenerative dementia. ${ }^{18,70}$ Occasionally, PET imaging with different tracers for biomarkers (eg, amyloid tracers with ${ }^{18} \mathrm{~F}$-florbetapir) in dementia may be indicated for the differential diagnosis of dementing disorders, especially in the presence of overlapping clinical features. ${ }^{71}$ Scanning with ${ }^{18} \mathrm{~F}$-florbetapir is not available in Hong Kong, but imaging with Pittsburgh Compound $\mathrm{B}$ and ${ }^{18} \mathrm{~F}$-flutametamol are available in Hong Kong. A local study has shown that ${ }^{18} \mathrm{FDG}$-PET with or without ${ }^{11} \mathrm{C}$-PIB brain imaging improved the accuracy of diagnosis of dementia subtype in $36 \%$ of a case series of Chinese dementia patients. ${ }^{72}$

Volumetric analysis of magnetic resonance imaging (MRI) may identify patterns of regional atrophy that are more specific in certain subtypes of dementia. In some studies, volumetric MRI has shown that patients with AD had a greater degree of hippocampal atrophy than patients with DLB had, and patients with DLB had more pronounced cortical atrophy than patients with Parkinson disease dementia. ${ }^{73,74}$

Although basic structural brain imaging (computed tomography or MRI) can be obtained in the primary care setting, highly specialised imaging is recommended for specialist settings only, as most studies using specialised modalities have focused on subtyping rather than the existence versus absence of dementia. ${ }^{46}$

\section{Laboratory tests}

Laboratory tests should be performed to identify infectious, metabolic, toxic, and inflammatory disorders that can cause neuropsychological impairment. The American Academy of Neurology recommends screening for vitamin B12 deficiency and hypothyroidism in patients with dementia. Screening for neurosyphilis is not recommended unless there is a high clinical suspicion. Because of the potential for both false positives and false negatives, genetic testing is not currently recommended unless a specific characteristic family history is present. Lumbar puncture, electroencephalography, and/or serologic tests may be useful in patients with dementia who are aged $<55$ years or in those with rapid progression, unusual dementia, or immunosuppression. ${ }^{12,18,75}$

\section{Cerebrospinal fluid biomarkers (total-tau and $\mathrm{p}$-tau)}

Cerebrospinal fluid biomarkers (including $\mathrm{A} \beta 42$ protein, total tau, and phospho-tau) are widely investigated biomarkers of AD and can be supportive of a diagnosis of AD but are not yet recommended for routine diagnostic purposes. ${ }^{30,76}$ None of these tests are valid as a standalone diagnostic test. These cerebrospinal fluid biomarkers can be measured only 
in private laboratory settings on a self-paid basis. Such tests are not well accepted in Hong Kong because of the invasiveness of collecting cerebrospinal fluid.

\section{Determining the underlying cause(s) of Mrs Wong's dementia}

Delirium or depression, which may mimic symptoms of dementia, should first be excluded. Medication history is checked to rule out any drugs with potential anticholinergic properties, which may also cause cognitive impairment.

With vascular risk factors (a history of hypertension and diabetes mellitus), there is a potential contributing cerebrovascular component to Mrs Wong's dementia. Mrs Wong did not have a history of clinical stroke and her dementia is of a slow progressive course, not one of the stroke-like episodes of stepwise decline, as might be the case in $\mathrm{VaD}$.

On physical examination, Mrs Wong was not found to have any Parkinsonism features or abnormal neurological signs that would be suggestive of dementia related to Parkinsonism. There were no features suggestive of DLB. Screening for other reversible causes of dementia, including thyroid disorder and vitamin B12 deficiency, were negative. Mrs Wong underwent a computed tomography scan of the brain, which showed mild cerebral atrophy and some periventricular ischaemia. On the basis of these findings, Mrs Wong met the clinical diagnostic criteria for AD.

\section{Role of primary healthcare professionals}

The World Alzheimer Report 2016 indicated that with the rising prevalence of dementia, the usual specialist-led approach may not expand rapidly enough to keep up with the increased need for care. Thus, primary and community care should have a more prominent role in improving the coverage of diagnosis and continuing dementia care. ${ }^{77}$

Screening for dementia among people at risk in primary care practices was found to significantly promote the recognition of dementia, but because of the risk of receiving a false-positive diagnosis, additional diagnostic assessment should be mandatory. ${ }^{78}$ Other perspectives exist on systematic consideration of the respective roles of primary and specialty care in long-range dementia care. ${ }^{79}$ Following recent research on the causes of and treatments for cognitive impairment, changes in clinical practice have occurred, and there is increased awareness of cognitive impairment detection during routine health check-ups in the primary care setting. The objectives of primary care physicians (PCPs) are to identify $\mathrm{AD}$ and other types of dementia, arrive at early diagnoses, and prevent and treat
AD complications such as falls and malnutrition. It is also important for PCPs to develop close interactions with specialists, including geriatricians, psychogeriatricians, and neurologists. ${ }^{80}$ For complex case diagnosis and management, a prompt referral to a specialist is required.

In one study, the collaborative care delivered by an interdisciplinary team resulted in a significant improvement in both the quality of care and BPSD among both primary care patients and their caregivers. ${ }^{81}$ Structured partnerships among primary healthcare professionals may serve as bridges between primary care, specialty care, and community-based services. ${ }^{82}$ To facilitate such management, it is advised that PCPs include a relevant history in the referral letter to facilitate subtyping of the patient's dementia (online supplementary Appendix).

Because of primary care providers' growing role, there is a need for better professional education and training in both diagnosis and management of dementia. In the United Kingdom, general practitioners work one session per week in their local Memory Clinics, where they can learn directly from experts and establish working relationships with secondary dementia caregivers. It is highly recommended that we adopt the same educational programme in Hong Kong. In addition, primary doctors can refer to the Hong Kong Reference Framework for Preventive Care for Older Adults in Primary Care Settings-Module for Cognitive Impairment (2017) written by the Primary Care Office, Department of Health. ${ }^{83}$

\section{Conclusion}

It is important that dementia is recognised at the earliest stage and that timely evaluations are carried out to initiate appropriate therapy, with patients able to participate in management decisions. The initial step in evaluation of a patient with suspected dementia should be the taking of a focused history of cognitive and behavioural changes, followed by a complete physical examination. Delirium, depression, and MCI should be considered in the differential diagnosis of memory impairment. Many useful screening tools are now available for dementia. Once a diagnosis of dementia has been made, neuroimaging (eg, brain computed tomography or MRI scan) and laboratory tests should be performed to rule out any reversible causes of dementia. Advanced imaging, such as FDG-PET imaging or amyloid PET scanning with special tracers, may be indicated for specific cases to reach a definitive diagnosis. In the future, primary care will play a more prominent role in dementia management. Close interactions between PCPs and specialists are needed for complex case management, especially those requiring pharmacological management. 


\section{Author contributions}

All authors have made substantial contributions to the concept or design of the study, acquisition of data, analysis or interpretation of data, drafting of the article, and critical revision for important intellectual content. All authors had full access to the data, contributed to the study, approved the final version for publication, and take responsibility for its accuracy and integrity.

\section{Acknowledgement}

The authors would like to thank Mr David CH Lau, who offered professional advice on cognitive tests.

\section{Conflicts of interest}

As an editor of the journal, JKH Luk was not involved in the peer review process of the article. Other authors have declared no conflicts of interest.

\section{Funding/support}

This research received no specific grant from any funding agency in the public, commercial, or not-for-profit sectors.

\section{References}

1. Qiu C, Kivipelto M, von Strauss E. Epidemiology of Alzheimer's disease: occurrence, determinants, and strategies toward intervention. Dialogues Clin Neurosci 2009;11:111-28.

2. Catindig JA, Venketasubramanian N, Ikram MK, Chen C. Epidemiology of dementia in Asia: insights on prevalence, trends and novel risk factors. J Neurol Sci 2012;321:11-6.

3. Prince M, Wimo A, Guerchet M, et al. World Alzheimer Report 2015-The Global Impact of Dementia. London: Alzheimer's Disease International; 2015.

4. Chan KY, Wang W, Wu JJ, et al. Epidemiology of Alzheimer's disease and other forms of dementia in China, 1990-2010: a systematic review and analysis. Lancet 2013;381:2016-23.

5. Prince M, Bryce R, Ferri C. World Alzheimer report 2011: The benefits of early diagnosis and intervention. London: Alzheimer's Disease International; 2011.

6. Boustani $\mathrm{M}$, Callahan $\mathrm{CM}$, Unverzagt $\mathrm{FW}$, et al. Implementing a screening and diagnosis program for dementia in primary care. J Gen Intern Med 2005;20:572-7.

7. Ross GW, Abbott RD, Petrovitch $\mathrm{H}$, et al. Frequency and characteristics of silent dementia among elderly JapaneseAmerican men. The Honolulu-Asia Aging Study. JAMA 1997;277:800-5.

8. Fahy M, Wald C, Walker Z, Livingston G. Secrets and lies: the dilemma of disclosing the diagnosis to an adult with dementia. Age Ageing 2003;32:439-41.

9. Tripathi M, Vibha D. Reversible dementias. Indian J Psychiatry 2009;51 Suppl 1:S52-5.

10. American Psychiatric Association. Diagnostic and Statistical Manual of Mental Disorders (DSM-5). 5th ed. Arlington, VA: Arlington; 2013.

11. Sachdev PS, Blacker D, Blazer DG, et al. Classifying neurocognitive disorders: the DSM-5 approach. Nat Rev Neurol 2014;10:634-42.

12. Ross GW, Bowen JD. The diagnosis and differential diagnosis of dementia. Med Clin North Am 2002;86:45576.

13. Howieson DB, Holm LA, Kaye JA, Oken BS, Howieson J.
Neurologic function in the optimally healthy oldest old. Neuropsychological evaluation. Neurology 1993;43:1882-6. 14. Small SA, Stern Y, Tang M, Mayeux R. Selective decline in memory function among healthy elderly. Neurology 1999;52:1392-6.

15. Crook T, Bartus RT, Ferris SH, Whitehouse P, Cohen GD, Gershon S. Age-associated memory impairment: proposed diagnostic criteria and measures of clinical change-report of a national institute of mental health work group. Dev Neuropsychol 1986;2:261-76.

16. Levy R. Aging-associated cognitive decline. Working Party of the International Psychogeriatric Association in collaboration with the World Health Organization. Int Psychogeriatr 1994;6:63-8.

17. Petersen RC, Smith GE, Waring SC, Ivnik RJ, Tangalos EG, Kokmen E. Mild cognitive impairment: clinical characterization and outcome. Arch Neurol 1999;56:303-8.

18. Petersen RC, Stevens JC, Ganguli M, Tangalos EG, Cummings JL, DeKosky ST. Practice parameter: early detection of dementia: mild cognitive impairment (an evidence-based review). Report of the Quality Standards Subcommittee of the American Academy of Neurology. Neurology 2001;56:1133-42.

19. Pandya SY, Clem MA, Silva LM, Woon FL. Does mild cognitive impairment always lead to dementia? A review. J Neurol Sci 2016;369:57-62.

20. Lopez OL, Becker JT, Chang YF, et al. Incidence of mild cognitive impairment in the Pittsburgh Cardiovascular Health Study-Cognition Study. Neurology 2012;79:1599606.

21. Yesavage JA, Brink TL, Rose TL, et al. Development and validation of a geriatric depression screening scale: a preliminary report. J Psychiatr Res 1982-1983;17:37-49.

22. Jorm AF, Fratiglioni L, Winblad B. Differential diagnosis in dementia. Principal components analysis of clinical data from a population survey. Arch Neurol 1993;50:72-7.

23. Andrew MK, Freter SH, Rockwood K. Prevalence and outcomes of delirium in community and non-acute care settings in people without dementia: a report from the Canadian Study of Health and Aging. BMC Med 2006;4:15.

24. Levkoff S, Cleary P, Liptzin B, Evans DA. Epidemiology of delirium: an overview of research issues and findings. Int Psychogeriatr 1991;3:149-67.

25. Vasilevskis EE, Han JH, Hughes CG, Wesley Ely E. Epidemiology and risk factors for delirium across hospital settings. Best Pact Res Clin Anaesthesiol 2012;26:277-87.

26. Leung JL, Leung VC, Leung CM, Pan PC. Clinical utility and validation of two instruments (the Confusion Assessment Method Algorithm and the Chinese version of Nursing Delirium Screening Scale) to detect delirium in geriatric inpatients. Gen Hosp Psychiatry 2008;30:171-6.

27. Rizzi L, Rosset I, Roriz-Cruz M. Global epidemiology of dementia: Alzheimer's and vascular types. Biomed Res Int 2014;2014:908915.

28. Vann Jones SA, O'Brien JT. The prevalence and incidence of dementia with Lewy bodies: a systematic review of population and clinical studies. Psychol Med 2014;44:67383.

29. Ballard C, Gauthier S, Corbett A, Brayne C, Aarsland D, Jones E. Alzheimer's disease. Lancet 2011;377:1019-31.

30. McKhann GM, Knopman DS, Chertkow H, et al. The diagnosis of dementia due to Alzheimer's disease: recommendations from the National Institute on Aging- 
Alzheimer's Association workgroups on diagnostic guidelines for Alzheimer's disease. Alzheimers Dement 2011;7:263-9.

31. Hachinski V, Iadecola C, Petersen RC, et al. National Institute of Neurological Disorders and StrokeCanadian Stroke Network vascular cognitive impairment harmonization standards. Stroke 2006;37:2220-41.

32. Román GC, Tatemichi TK, Erkinjuntti T, et al. Vascular dementia: diagnostic criteria for research studies. Report of the NINDS-AIREN International Workshop. Neurology 1993;43:250-60.

33. McKeith IG, Boeve BF, Dickson DW, et al. Diagnosis and management of dementia with Lewy bodies: fourth consensus report of the DLB Consortium. Neurology 2017;89:88-100.

34. Olney NT, Spina S, Miller BL. Frontotemporal dementia. Neurol Clin 2017;35:339-74.

35. Rascovsky K, Hodges JR, Knopman D, et al. Sensitivity of revised diagnostic criteria for the behavioural variant of frontotemporal dementia. Brain 2011;134(Pt 9):2456-77.

36. Finkel SI, Silva JC, Cohen GD, Miller S, Sartorius N. Behavioral and psychological symptoms of dementia: a consensus statement on current knowledge and implications for research and treatment. Am J Geriatr Psychiatry 1998;6:97-100.

37. International Psychogeriatric Association. The IPA complete guides to behavioral and psychological symptoms of dementia. Milwaukee, WI; 2010.

38. Hersch EC, Falzgraf S. Management of the behavioral and psychological symptoms of dementia. Clin Interv Aging 2007;2:611-21.

39. Tible OP, Riese F, Savaskan E, von Gunten A. Best practice in the management of behavioural and psychological symptoms of dementia. Ther Adv Neurol Disord 2017;10:297-309.

40. Bessey LJ, Walaszek A. Management of behavioral and psychological symptoms of dementia. Curr Psychiatry Rep 2019;21:66.

41. Pedrinolla A, Tamburin S, Brasioli A, et al. An indoor therapeutic garden for behavioral symptoms in Alzheimer's disease: a randomized controlled trial. J Alzheimers Dis 2019;71:813-23.

42. Luk JH. Pharmacological management of behavioural and psychological symptoms of dementia. Asian J Gerontol Geriatr 2017;12:65-8.

43. Bjerre LM, Farrell B, Hogel M, et al. Deprescribing antipsychotics for behavioural and psychological symptoms of dementia and insomnia: evidence-based clinical practice guideline. Can Fam Physician 2018;64:17-27.

44. Huang SS, Lee MC, Liao YC, Wang WF, Lai TJ. Caregiver burden associated with behavioral and psychological symptoms of dementia (BPSD) in Taiwanese elderly. Arch Gerontol Geriatr 2012;55:55-9.

45. Knopman DS, Boeve BF, Petersen RC. Essentials of the proper diagnoses of mild cognitive impairment, dementia, and major subtypes of dementia. Mayo Clin Proc 2003;78:1290-308.

46. Pink J, O’Brien J, Robinson L, Longson D; Guideline Committee. Dementia: assessment, management and support: summary of updated NICE guidance. BMJ 2018;361:k2438.

47. Campbell NL, Boustani MA, Lane KA, et al. Use of anticholinergics and the risk of cognitive impairment in an
African American population. Neurology 2010;75:152-9. 48. Shea YF, Chu LW, Chan AO, Ha J, Li Y, Song YQ. A systematic review of familial Alzheimer's disease: differences in presentation of clinical features among three mutated genes and potential ethnic differences. J Formos Med Assoc 2016;115:67-75.

49. Shea YF, Chu LW, Lee SC, Chan AO. The first case series of Chinese patients in Hong Kong with familial Alzheimer's disease compared with those with biomarker-confirmed sporadic late-onset Alzheimer's disease. Hong Kong Med J 2017;23:579-85.

50. Brown J. The use and misuse of short cognitive tests in the diagnosis of dementia. J Neurol Neurosurg Psychiatry 2015;86:680-5.

51. Creavin S, Wisniewski S, Noel-Storr A, Cullum S; MMSE review team. Cognitive tests to help diagnose dementia in symptomatic people in primary care and the community. Br J Gen Pract 2018;68:149-50.

52. Folstein MF, Folstein SE, McHugh PR. "Mini-mental state". A practical method for grading the cognitive state of patients for the clinician. J Psychiatr Res 1975;12:189-98.

53. Tangalos EG, Smith GE, Ivnik RJ, et al. The Mini-Mental State Examination in general medical practice: clinical utility and acceptance. Mayo Clin Proc 1996;71:829-37.

54. Chiu HF, Lee HC, Chung WS, Kwong PK. Reliability and validity of the Cantonese version of Mini-Mental State Examination-a preliminary study. JHKC Psych 1994;4:258.

55. Chiu HF, Lam C, Chi I, et al. Prevalence of dementia in Chinese elderly in Hong Kong. Neurology 1998;50:1002-9.

56. Anthony JC, LeResche L, Niaz U, von Korff MR, Folstein MF. Limits of the 'Mini-Mental State' as a screening test for dementia and delirium among hospital patients. Psychol Med 1982;12:397-408.

57. Crum RM, Anthony JC, Bassett SS, Folstein MF. Populationbased norms for the Mini-Mental State Examination by age and educational level. JAMA 1993;269:2386-91.

58. Creavin ST, Wisniewski S, Noel-Storr AH, et al. MiniMental State Examination (MMSE) for the detection of dementia in clinically unevaluated people aged 65 and over in community and primary care populations. Cochrane Database Syst Rev 2016;(1):CD011145.

59. Nasreddine ZS, Phillips NA, Bédirian V, et al. The Montreal Cognitive Assessment, MoCA: a brief screening tool for mild cognitive impairment. J Am Geriatr Soc 2005;53:6959.

60. Rossetti HC, Lacritz LH, Cullum CM, Weiner MF. Normative data for the Montreal Cognitive Assessment $(\mathrm{MoCA})$ in a population-based sample. Neurology 2011;77:1272-5.

61. Yeung PY, Wong LL, Chan CC, Leung JL, Yung CY. A validation study of the Hong Kong version of Montreal Cognitive Assessment (HK-MoCA) in Chinese older adults in Hong Kong. Hong Kong Med J 2014;20:504-10.

62. Wong A, Nyenhuis D, Black SE, et al. Montreal Cognitive Assessment 5-minute protocol is a brief, valid, reliable, and feasible cognitive screen for telephone administration. Stroke 2015;46:1059-64.

63. Washington University in St Louis. $C D R \circledast$ Dementia Staging Instrument. Available from: https://knightadrc. wustl.edu/cdr/cdr.htm. Accessed 30 Aug 2019.

64. Morris JC. The Clinical Dementia Rating (CDR): current version and scoring rules. Neurology 1993;43:2412-4. 
65. Mini-Cog(-Screening for cognitive impairment in older adults. Available from: https://mini-cog.com/. Accessed 30 Aug 2019.

66. Borson S, Scanlan J, Brush M, Vitaliano P, Dokmak A. The Mini-Cog: a cognitive 'vital signs' measure for dementia screening in multi-lingual elderly. Int J Geriatr Psychiatry 2000;15:1021-7.

67. Galvin JE, Roe CM, Xiong C, Morris JC. Validity and reliability of the AD8 informant interview in dementia. Neurology 2006;67:1942-8.

68. Shaik MA, Khoo CH, Thiagarajah AG, et al. Pilot evaluation of a dementia case finding clinical service using the informant AD8 for at-risk older adults in primary health care: a brief report. J Am Med Dir Assoc 2016;17:673.e5-8.

69. Cahn DA, Salmon DP, Butters N, et al. Detection of dementia of the Alzheimer type in a population-based sample: neuropsychological test performance. J Int Neuropsychol Soc 1995;1:252-60.

70. Corey-Bloom J, Thal LJ, Galasko D, et al. Diagnosis and evaluation of dementia. Neurology 1995;45:211-8.

71. Berti V, Pupi A, Mosconi L. PET/CT in diagnosis of dementia. Ann N Y Acad Sci 2011;12281:81-92.

72. Shea YF, Ha J, Lee SC, Chu LW. Impact of 18FDG PET and $11 C$-PIB PET brain imaging on the diagnosis of Alzheimer's disease and other dementias in a regional memory clinic in Hong Kong. Hong Kong Med J 2016;22:327-33.

73. Barber R, Ballard C, McKeith IG, Gholkar A, O’Brien JT. MRI volumetric study of dementia with Lewy bodies; a comparison with $\mathrm{AD}$ and vascular dementia. Neurology 2000;54:1304-9.

74. Beyer MK, Larsen JP, Aarsland D. Gray matter atrophy in Parkinson disease with dementia and dementia with Lewy bodies. Neurology 2007;69:747-54.
75. Geschwind MD, Shu H, Haman A, Sejvar JJ, Miller BL. Rapidly progressive dementia. Ann Neurol 2008;64:97108.

76. Shea YF, Chu LW, Zhou L, et al. Cerebrospinal fluid biomarkers of Alzheimer's disease in Chinese patients: a pilot study. Am J Alzheimers Dis Other Demen 2013;28:769-75.

77. Prince M, Comas-Herrera A, Knapp M, Guerchet M, Karagiannidou M. World Alzheimer Report 2016improving healthcare for people living with dementia: coverage, quality and costs now and in the future. London: Alzheimer's Disease International; 2016.

78. Eichler T, Thyrian JR, Hertel J, et al. Rates of formal diagnosis of dementia in primary care: the effect of screening. Alzheimers Dement (Amst) 2015;1:87-93.

79. Borson S, Frank L, Bayley PJ, et al. Improving dementia care: the role of screening and detection of cognitive impairment. Alzheimers Dement 2013;9:151-9.

80. Cohen CA, Pringle D, LeDuc L. Dementia caregiving: the role of the primary care physician. Can J Neurol Sci 2001;28 Suppl 1:S72-6.

81. Callahan CM, Boustani MA, Unverzagt FW, et al Effectiveness of collaborative care for older adults with Alzheimer disease in primary care: a randomized controlled trial. JAMA 2006;295:2148-57.

82. Reuben DB, Roth CP, Frank JC, et al. Assessing care of vulnerable elders-Alzheimer's disease: a pilot study of a practice redesign intervention to improve the quality of dementia care. J Am Geriatr Soc 2010;58:324-9.

83. Hong Kong Reference Framework for Preventive Care for Older Adults in Primary Care Settings. Module on Cognitive Impairment. Department of Health, Hong Kong SAR Government; 2017. 